\title{
Effects of the Sri Lankan medicinal plant, Salacia reticulata, in rheumatoid arthritis
}

\author{
Yuusuke Sekiguchi $\cdot$ Hiroshi Mano $\cdot$ \\ Sachie Nakatani $\cdot$ Jun Shimizu $\cdot$ Masahiro Wada
}

Received: 27 July 2009/Accepted: 5 August 2009/Published online: 2 September 2009

(C) Springer-Verlag 2009

\begin{abstract}
Salacia reticulata is a native plant of Sri Lanka. In the traditional medicine of Sri Lanka and India, Salacia reticulata bark is considered orally effective in the treatment of rheumatism, gonorrhea, skin disease and diabetes. We have investigated, both in vivo and in vitro, whether the leaf of Salacia reticulata (SRL) can ameliorate collagen antibody-induced arthritis (CAIA) in mice as the rheumatoid arthritis (RA) model. The mice were fed a lard containing chow diet (AIN-93G) or the same diet containing $1 \%(\mathrm{w} / \mathrm{w})$ SRL powder. All mice were bred for 23 days. On day 7 or 14 after LPS injection, mice were killed, and tissue and blood samples were collected. Histological analysis was performed, and serum levels of inflammatory mediators and the mRNA levels of inflammation-related genes and osteoclast-related genes were measured. SRL treatment ameliorated the rapid initial paw swelling, inflammatory cells infiltration, skeletal tissues damage, osteoclast activation and the mRNA levels for osteoclast-related genes compared with the CAIA mice. However, the serum and mRNA levels of inflammatory mediators did not differ between the CAIA mice and the SRL-treated mice. SRL might reduce the inflammatory cells induction and skeletal tissue degradation by CAIA by the regulating osteoclastogenesis.
\end{abstract}

This article belongs to a special issue on the 4th international Niigata symposium on diet and health, 29-30 November 2008.

Y. Sekiguchi · H. Mano - S. Nakatani · J. Shimizu .

M. Wada ( $\square)$

Department of Clinical Dietetics and Human Nutrition,

Faculty of Pharmaceutical Sciences, Josai University,

1-1 Keyakidai, Sakado, Saitama 350-0295, Japan

e-mail: fs517@josai.ac.jp
Keywords CAIA - Osteoclast - Pannus - RANKL . Rheumatoid arthritis $\cdot$ Salacia reticulata

\section{Introduction}

Salacia reticulata (SR) is a plant native to Sri Lanka. In the traditional medicine, called "Ayurveda," the roots and stems of SR have been used for prevention of rheumatism, gonorrhea, skin disease and diabetes. The effects of SR on diabetes have already been reported. For example, it is known that SR contains such unique compounds as salacinol, kotalanol and mangiferin [30]. Salacinol and kotalanol were reported to inhibit $\alpha$-glucosidase activity [28], while Mangiferin was reported to decrease the expression of fructose-1,6-bisphosphatase (FBP), a key enzyme involved in gluconeogenesis in the liver [9]. However, no studies are available on the effects of SR on rheumatoid arthritis (RA) at biochemical and biophysical level. Accordingly, we investigated if the leaf of SR (SRL) could be considered a possible prophylactic/therapeutic agent in RA.

Rheumatoid arthritis is a chronic inflammatory disease, characterized by inflammatory cell infiltration, synovial hyperplasia and destruction of cartilage and bone. Although the etiology of RA is not yet fully understood, recent studies have suggested an involvement of autoantibody production, immune complex formation, inflammatory cell infiltration and tumor-like proliferation of synovium "pannus" in the pathogenesis of RA [6, 16, 20]. In addition, activation of osteoclasts in RA is associated with skeletal tissue destruction $[2,7,18,19]$. RA treatment is currently mainly based on the administration of nonsteroidal anti-inflammatory drugs (NSAID), corticosteroid preparation, disease-modifying anti-rheumatic drugs and 
molecularly targeted drugs such as indomethacin, prednisolone, methotrexate and infliximab [26]. However, many drugs only provide symptomatic treatment, and there is no fundamental treatment for RA.

When RA develops, inflammatory mediators such as interleukin (IL) and prostaglandin are released into the whole joint and blood. Especially, tumor necrosis factoralpha (TNF- $\alpha)$, IL- $1 \beta$ and IL- 6 have often been used as indices of the severity of RA symptoms. Moreover, there have been attempts to administer immunomodulators such as or interferon (IFN)- $\gamma$ and anti-pro-inflammatory cytokines such as IL-10 [3]. However, no effective medical treatment has been established.

A granulation tissue called "pannus" is involved in RA. The presence of osteoclasts in pannus of skeletal tissue in RA has been confirmed [2]. Pannus releases several proinflammatory mediators, matrix metalloproteinase (MMP), immune modulatory factors and bone metabolism-related factors [27]. It was thought that osteoclastogenesis is enhanced by release of factors such as ILs, TNF- $\alpha$ and receptor activator of nuclear factor-kappa $B$ ligand (RANKL) from pannus [23]. Activated osteoclasts have been shown to stain for tartrate-resistant acid phosphatase [25]. Moreover, the transcription factor c-fos is essential for osteoclast differentiation. Expression of RANKL and c-fos genes is elevated in RA [21]. Here, we report a study on RA in CAIA mice treated with SR by histological and the genes expression analyses.

\section{Methods}

\section{Salacia reticulata}

Leaves of Salacia reticulata (Hippocrateaceae) plants cultivated in Sri Lanka were purchased from Ayurveda Kothalahimbutu Association (Tokyo, Japan). The plant species was identified by Dr. G. A. S. Premakumara, at Herbal Technology Section, Industrial Technology Institute (Colombo, Sri Lanka). Fresh leaves were sun-dried. After the removal of damaged leaves, dried intact leaves were pulverized in a food mill (Panasonic Corporation, Osaka, Japan) and filtered though a $150-\mu \mathrm{m}$ mesh sieve to obtain a powder.

Animals and treatments

Male DBA/1 J mice (5-week-old, $n=36$ ) were purchased from Charles River Japan (Yokohama, Japan). The mice were housed in plastic cages under the constant temperature $\left(25 \pm 3^{\circ} \mathrm{C}\right)$ and on a 12-h light/dark cycle. Experiments were performed after 1 week of acclimatization. Under standardized conditions, 6-week-old mice were divided into three groups: an untreated group (normal control), a collagen antibody induced-arthritis group (CAIA) and a CAIA plus SRL-treated group (CAIA + SRL). Each group consists of a combination of day 7 with day 14 after LPS injection. Both control and CAIA mice were fed with a AIN-93G diet, where fat is provided by lard and corn instead of soybean. The ratio of lard/corn oil was about 5:1 [13]. The CAIA + SRL mice were fed with AIN-93G containing 1\% (w/w) SRL powder. All mice were given free access to each diet and tap water for 23 days. CAIA was induced by utilizing an arthritogenic cocktail of monoclonal antibodies to type II collagen (mAb, Chondrex, Redmond, WA, USA) combined with lipopolysaccharide (LPS) simulation in accordance with Terato's method, as previously described [10, 15]. Briefly, mice were intraperitoneally injected with $2 \mathrm{mg}$ of $\mathrm{mAb}$ on day -2 and day -1 (4 mg total) with $50 \mu \mathrm{g}$ of LPS on day 0 as shown in Fig. 1. After the onset of arthritis, mice were scored (0-16) in a common manner. Accordingly the degree of paw swelling and the thickness of foot were measured by slide caliper every day for 2 weeks as signs of arthritis [17]. Each limb was graded individually on a scale of $0-4$, where $0=$ normal, $1=$ mild but definite redness and swelling of the ankles or redness and swelling of any degree in any single digit, $2=$ moderate to severe redness and swelling of the ankles, 3 = redness and swelling of the entire foot including the digits, and $4=$ maximally inflamed limb, with involvement of multiple joints. The maximum cumulative clinical arthritis score for each mouse was 16 [12]. All animal experiments were approved by the Institutional Animal Care and Use Committee of Josai University.

\section{Histological analysis}

Mouse hind paw fingers were collected and sequentially immersion-fixed in $10 \%$ paraformaldehyde/0.1 M phosphate buffer (PB) $\mathrm{pH} 7.4,12.5 \%$ glucose/0.1 M PB pH 7.4, and $25 \%$ glucose/0.1 M PB pH 7.4, for each two days. After the toes were decalcified using 5\% ethylenediaminetetraacetic acid (EDTA)/25\% glucose/0.1 M PB pH 7.4 for 2 days. They were routinely processed and embedded in $4 \%$ carboxy methyl cellulose. Standard sagittal sections measuring $5 \mu \mathrm{m}$ in thickness were prepared from the frozen and fixed toe using a cryostat CM3050S (LIECA, Tokyo, Japan). The joint spaces were histologically assessed on the sections, and histological scores (0-3) were assigned based on a previously reported scoring method [8]. The sections were stained with Mayer's hematoxylin and eosin (HE), toluidine blue (TB) pH 7.0 and tartrateresistant acid phosphatase (TRAP). Scoring of sections based on inflammatory cell infiltration in the joint space and skeletal tissue destruction was performed using a scale 
Fig. 1 Paw swelling score in CAIA and CAIA + SRL mice. Arthritis was induced in mice by ip injection of anti-type II collagen monoclonal antibody $(\mathrm{mAb})$ and lipopolysaccharide (LPS). The day of LPS injection was defined as day 0 of arthritis. Each group of mice was started on its specified diet 8 days prior to LPS injection. Paw swelling was measured from day 0 to day 14. Paw swelling score was calculated by micro caliper and visual analog scale. Values are the means $\pm \mathrm{SD}(n=6)$. $* P<0.05$ versus CAIA

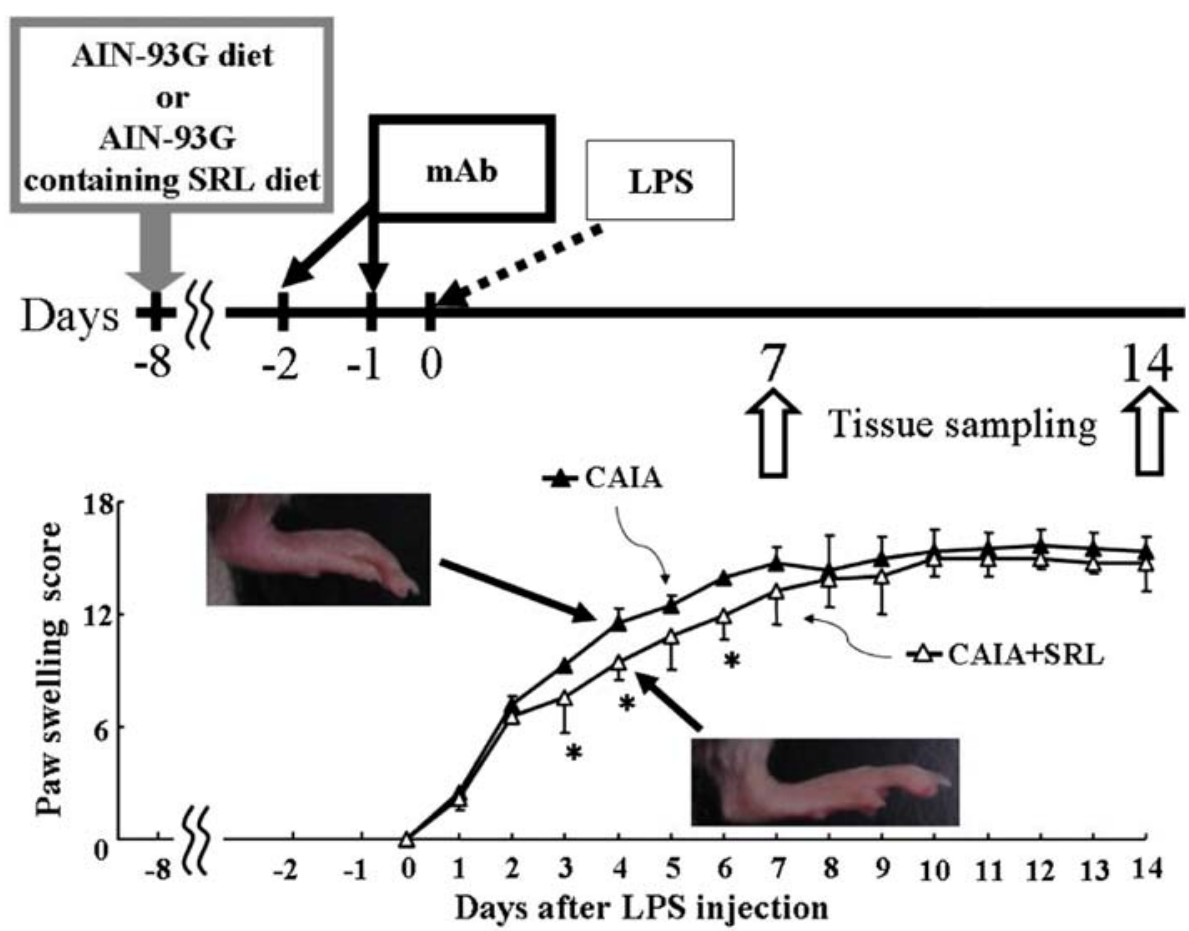

of $0-3$ ( 0 with in normal limits; 1 minimal; 2 mild; 3 severe) essentially as described previously [8]. A leukocyte acid phosphatase kit (Sigma-Aldrich Corp, Tokyo, Japan) was used for TRAP activity staining. Osteoclasts (TRAPpositive multinucleate cells containing three or more nuclei) located at the bone surface were counted in each slide [1].

$\mathrm{PGE}_{2}$ and IL- $1 \beta$ analyses

Blood was drawn from the heart of 36 mice on days 7 and 14. Blood was put on ice for $30 \mathrm{~min}$ and centrifuged for $20 \mathrm{~min}$ at $13,370 \times g$ in a centrifuge separator. The first supernatant was collected and centrifuged for $20 \mathrm{~min}$ at $13,370 \times g$. The second supernatant was used as serum sample. Serum $\mathrm{PGE}_{2}$ level was measured by enzyme immunoassay (EIA) using a PGE $_{2}$ kit (Prostaglandin E2 Express EIA kit; Cayman Chemical, Ann Arbor, MI, USA). Serum IL-1 $\beta$ level was measured by enzyme-linked immunosorbent assay (ELISA) using a murine IL- $1 \beta$ kit (Quantikine; R\&D Systems, Minneapolis, MN, USA).

RNA extraction and reverse transcription (RT)-PCR

The hind toe or knee joints, cleaned of surrounding muscle and skin, were used for RNA extraction. The joint tissues were cut into small pieces, which were then homogenized in TRIzol reagent (Invitrogen, Tokyo, Japan). The homogenized tissue in TRIzol reagent was centrifuged for $20 \mathrm{~min}$ at $13,370 \times g$ in a centrifuge separator, and the first supernatant was collected and filtered though a $0.45-\mu \mathrm{m}$ Millex-FH (Millipore, Japan) hydrophobic filter. The filtered supernatant was centrifuged for $20 \mathrm{~min}$ at $13,370 \times \mathrm{g}$, and the second supernatant was subjected to RNA extraction. RNA was extracted using TRIzol reagent according to the manufacturer's instructions (Invitrogen, Japan). After dissolution in diethylpyrocarbonate-treated water, the RNA was quantified using a spectrophotometer. The Singlestrand cDNA was prepared from $1 \mu \mathrm{g}$ of total RNA using the SuperScript First-Strand Synthesis System for RT-PCR (Invitrogen, Tokyo, Japan). Amplification was performed in $10 \mu \mathrm{l}$ of reaction mixture using EX taq (TAKARA BIO INC, Shiga, Japan). The primer sequences used for each $\mathrm{PCR}$ are given below. Initial denaturation was performed at $94^{\circ} \mathrm{C}$ for $30 \mathrm{~s}$, annealing was performed at $58^{\circ} \mathrm{C}$ for $30 \mathrm{~s}$, and extension was performed at $72^{\circ} \mathrm{C}$ for $3 \mathrm{~min}$ to conclude the reaction. Transcribed cDNA was subjected to PCR amplification using primers specific for the investigated genes as shown in Table 1. The PCR program was initiated by $5 \mathrm{~min}$ at $94^{\circ} \mathrm{C}$ before 30 thermal cycles for TNF- $\alpha$, IL-1 $\beta$, MMP-2, MMP-3, MMP-9 and cathepsin K, 35 thermal cycles for GAPDH, IL-6, c-fos and RANKL, and 40 thermal cycles for IL-10 and IFN- $\gamma$. Those thermal cycles each consisted of $30 \mathrm{~s}$ at $94^{\circ} \mathrm{C}, 30 \mathrm{~s}$ at $58^{\circ} \mathrm{C}$ and $3 \mathrm{~min}$ at $72^{\circ} \mathrm{C}$. The PCR products were separated on $2 \%$ agarose gel with tris-acetate-EDTA buffer and visualized with ethidium bromide. All gels were digitally imaged using a flat head scanner and Adobe Photoshop 7.0 software. Within each series, all adjustments were made in parallel to all gels used for comparison. The band 
intensities of these digital images were determined using ImageJ software (National Institutes of Health, USA). The results for each mRNA level were normalized against the GAPDH mRNA level. Data are presented as the fold change in the target/GAPDH ratio.

\section{Statistical analysis}

Results are expressed as mean with standard deviation (SD) of six mice. Statistical analysis was carried out with StatMate III Version3.18 (ATMS Co., Ltd. Tokyo, Japan). Distributed data were compared via paired $t$ test.

\section{Results}

First of all we investigated whether SRL affected paw swelling observed in CAIA arthritis. As expected, normal control mice developed no symptoms of arthritis (data not shown). In both CAIA mice and CAIA + SRL mice, the first visual sign of paw swelling appeared on day 1 after LPS injection, and the swelling gradually increased thereafter (Fig. 1). The swelling was quantified by gross observation and measurement of the foot thickness with slide calipers from day 0 through day 14 after LPS injection. The swelling score in CAIA mice was $2.3 \pm 1.2$ on day 1 , and the maximum paw swelling score was $15.6 \pm 0.8$ on day 12 . In CAIA + SRL mice, paw swelling score was of $2.3 \pm 1.0$ on day 1 rising to a maximum of $15.5 \pm 0.8$ on day 10 . The statistical analysis indicated that SRL treatment affected the increase in paw swelling from day 2 through day 14, with the suppression being statistically significant on days 3,4 and 6 . On the other hand, SRL did not affect the paw swelling from day 7 to day 14.

We next investigated whether the inflammatory cell infiltration that is characteristic of CAIA was ameliorated by SRL. On days 7 and 14, 36 mice were killed in each group, and 36 paws were harvested to obtain toe joints. Normal control mice showed no inflammatory cells in the toe joint space on days 7 and 14 (Fig. 2). CAIA mice showed a markedly increase in inflammatory cells in the toe joint space on days 7 and 14 compared with normal control mice. On the other hand, although CAIA + SRL mice also showed a marked increase in inflammatory cells in the joint space on day 7 compared with normal control mice, on day 14 the inflammatory cell infiltration was tended to decrease compared with in the CAIA mice on day 14.

We then analyzed whether the skeletal tissue damage that is characteristic of CAIA was affected by SRL. On days 7 and 14, 36 mice were killed in each group and toe joints were harvested. Toe joint sections prepared as described above were stained with toluidine blue at $\mathrm{pH} 7.0$ (TB), and the joint spaces were histologically assessed on the sections, and the histological scores (0-3) were assigned on the basis of a previously described scoring method. Normal control mice showed no skeletal tissue damage in the toe joints on day 7 or 14 (Fig. 3). On the other hand, CAIA mice showed marked skeletal tissue damage in toe joints on days 7 and 14. CAIA + SRL mice also showed marked skeletal tissue damage on day 7, but a significant effect of SRL treatment on skeletal tissue damage in the toe joint was present on day 14 .

Table 1 Sequences of PCR primers used

\begin{tabular}{llll}
\hline Target gene & Sequence & Target gene & Sequence \\
\hline GAPDH forward & $5^{\prime}$-TTGACCTCAACTACATGG-3' & MMP-2 forward & $5^{\prime}$-CAGTGACACCACGTGACAAG-3' \\
GAPDH reverse & $5^{\prime}$-CAGGGTGGTGGACCTCAT-3' & MMP-2 reverse & $5^{\prime}$-CATTCCAGGAGTCTGCGATG-3' \\
TNF- $\alpha$ forward & $5^{\prime}$-CGCTCTTCTGTCTACTGAAC-3' & MMP-3 forward & $5^{\prime}$-CCAGTCTACAAGTCCTCCAC-3' \\
TNF- $\alpha$ reverse & $5^{\prime}$-GTCCCTTGAAGAGAACCTGG-3' & MMP-3 reverse & $5^{\prime}$-GCAGCATCCATGTTGGATGG-3' \\
IL-1 $\beta$ forward & $5^{\prime}$-GCTGTCCAGATGAGAGCATC-3' & MMP-9 forward & $5^{\prime}$-CTGCCTGCACCACTAAAG-3' \\
IL-1 $\beta$ reverse & $5^{\prime}$-CTGTCCATTGAGGTGGAGAG-3' & MMP-9 reverse & $5^{\prime}$-GTACAGGAAGAGTACTGC-3' \\
IL-6 forward & $5^{\prime}$-CAGTTGCCTTCTTGGGACTG-3' & c-fos forward & $5^{\prime}$-GATACACTCCAAGCGGAGAC-3' \\
IL-6 reverse & $5^{\prime}$-CGTAGTCCAGAAGACCAGAG-3' & c-fos reverse & $5^{\prime}$-CCAGTCTGCTGCATAGAAGG-3' \\
IL-10 forward & $5^{\prime}$-CAATAACTGCACCCACTTCC-3' & RANKL forward & $5^{\prime}$-GAGCGCAGATGGATCCTAAC-3' \\
IL-10 reverse & $5^{\prime}$-ATTCATGGCCTTGTAGACAC-3' & RANKL reverse & $5^{\prime}$-GCAGCATTGATGGTGAGGTG-3' \\
IFN- $\gamma$ forward & $5^{\prime}$-GATATCTGGAGGAACTGG-3' & Cathepsin K forward & $5^{\prime}$-CCAGTGTGGTTCCTGTTGG-3' \\
IFN- $\gamma$ reverse & $5^{\prime}$-GACTCCTTTTCCGCTTCC-3' & Cathepsin K reverse & $5^{\prime}$-TTGCCGTGGCGTTATACAT-3' \\
\hline
\end{tabular}

$G A P D H$ glyceraldehyde 3-phosphate dehydrogenase; $I L$ interleukin; $I F N$ interferon; $M M P$ matrix metallo proteinase; $P C R$ polymerase chain reaction; RANKL receptor activator of NF- $\kappa \mathrm{B}$ ligand; $T N F$ tumor necrosis factor 
A
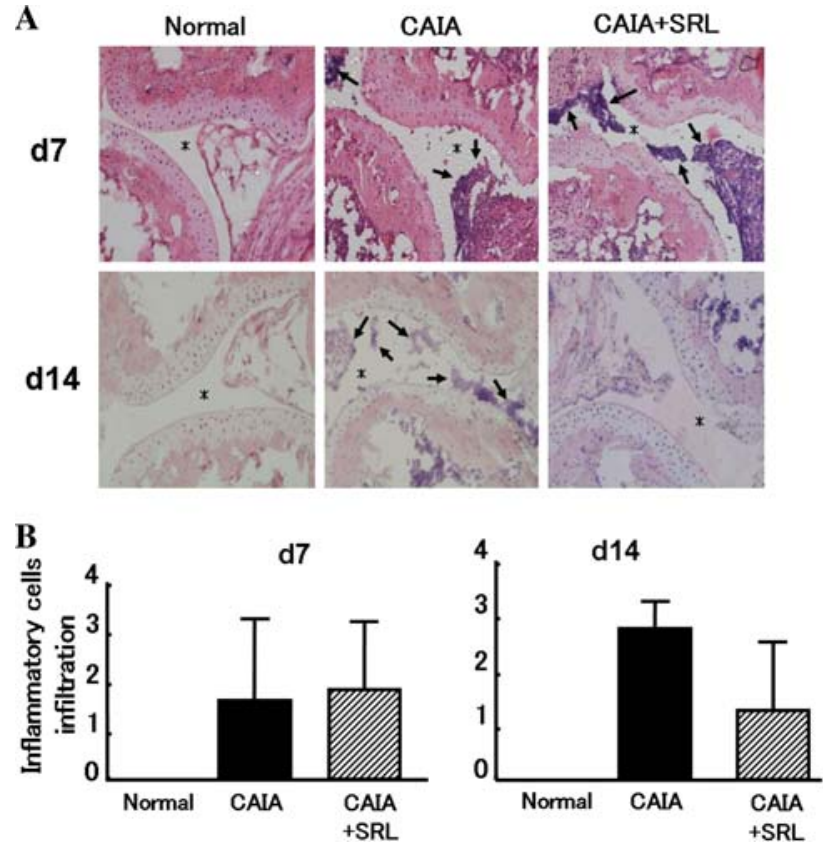

Fig. 2 Toe joints inflammatory cells in CAIA and CAIA + SRL mice. Sections were prepared from toe joints of mice on days 7 and 14 after LPS injection. The sections were stained with Mayer's hematoxylin and eosin (HE) (a). Histological scores for inflammatory cell infiltration were graded as follows: $0=$ within normal limits; $1=$ slight infiltration; $2=$ mild infiltration; $3=$ severe infiltration (b). Values are the means $\pm \mathrm{SD}(n=6)$. Arrows inflammatory cell; asterisks joint space; bar $100 \mu \mathrm{m}$

To clarify whether SRL suppressed the inflammatory mediators involved in arthritis, we analyzed the serum concentrations and the mRNA levels of various inflammatory mediators. Mice ( $n=6 /$ group) were killed, and the blood and the toe joints were collected on days 7 and 14 . The serum concentration of $\mathrm{PGE}_{2}$ in CAIA mice was about 15 -fold higher than in the normal control mice on day 7. The serum concentration of $\mathrm{PGE}_{2}$ in CAIA mice was significantly $(P<0.05)$ higher, threefold than the normal mice, on day 14. There were no differences between the serum concentrations of $\mathrm{PGE}_{2}$ of CAIA and CAIA + SRL mice. On the other hand, serum concentration of IL-1 in CAIA mice was about threefold higher than in the normal control mice $(P<0.05)$. However, the serum concentration of IL-1 in CAIA mice was not differed to the normal mice on day 14 (Fig. 4). Serum IL-1 concentrations in the CAIA mice and the CAIA + SRL mice did not differ on day 14. Serum concentrations of IL- $1 \beta$ and $\mathrm{PGE}_{2}$, and mRNA levels of TNF- $\alpha$, IL- $1 \beta$, IL-6, IL-10 and IFN- $\gamma$ were not affected by SRL administration (Fig. 4).

Total RNA was extracted from knee joints. The expression of genes encoding TNF- $\alpha$, IL-1, IL-6, IL-10 and IFN- $\gamma$ was examined by RT-PCR. The mRNA levels for IL- $1 \beta$ and IL-6 in CAIA mice were about three- and twofold higher, respectively, compared with in the normal
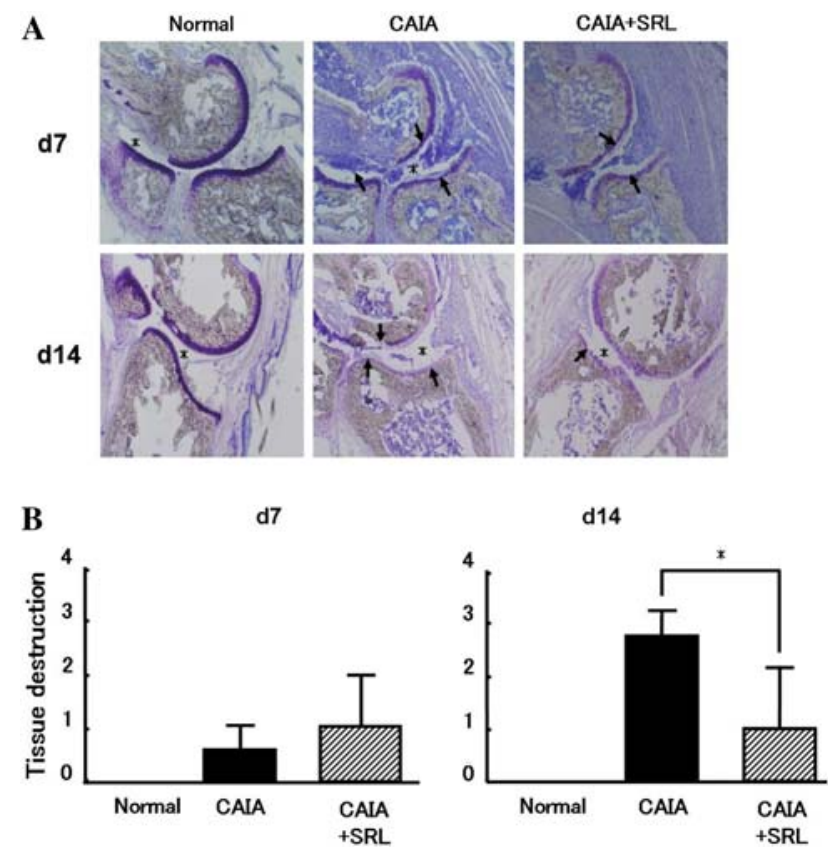

Fig. 3 Toe joints skeletal tissue in CAIA and CAIA + SRL mice. Sections were prepared from toe joints of mice on days 7 and 14 after LPS injection. The sections were stained with toluidine blue (TB) $\mathrm{pH}$ 7.0 (a). Histological scores for skeletal tissue damage was graded as described for Fig. $2 b$. Values are the means $\pm \operatorname{SD}(n=6)$. $* P<0.05$ versus CAIA. Arrows tissue damage; asterisks joint space; bar $200 \mu \mathrm{m}$

control mice (Fig. 5). The mRNA levels of TNF- $\alpha$, IL-10 and IFN- $\gamma$ did not differ between CAIA mice and the normal control mice. The mRNA levels of TNF- $\alpha$, IL-1, IL-6, IL-10 and IFN- $\gamma$ were similar in CAIA + SRL and the CAIA mice. The mRNA levels encoding for RANKL, MMP-2, MMP-3, c-fos and cathepsin K were markedly decreased by SRL intake.

Total RNA was similarly extracted from toe joints. The expression of the genes encoding RANKL, MMP-2, MMP3, MMP-9, cathepsin K and c-fos was examined by RTPCR (Fig. 6). The mRNA levels for RANKL, MMP-2, MMP-3, MMP-9, cathepsin $\mathrm{K}$ and c-fos in CAIA mice were two-, seven-, ten-, two-, five- and threefold higher, respectively, in comparison with normal control mice. SRL treatment was associated with a significant decrease of mRNA levels for RANKL, MMP-2, MMP-3, MMP-9, cathepsin $\mathrm{K}$ and c-fos in CAIA + SRL by one-half, twothirds, one-half, one-half and one-half, respectively, compared with CAIA mice.

We finally investigated whether the administration of SRL affected bone resorption by osteoclasts. We analyzed the activation of osteoclasts in mouse toe joints by TRAP staining (Fig. 7). TRAP-positive cells were detected in the bone of normal mice and assigned to be osteoclasts. TRAPpositive osteoclasts were found to dramatically increase in the toe joints of CAIA mice. On the other hand, 
Fig. 4 Levels of inflammatory mediators in the serum of normal control, CAIA and CAIA + SRL mice. Serum was obtained from mice on days 7 and 14 after LPS injection. Serum prostaglandin E2 $\left(\mathrm{PGE}_{2}\right)$ and interleukin 1-beta (IL-1 $\beta)$ were measured by enzyme immunosorbent assay (ELISA). Values are the means \pm SD $(n=6)$

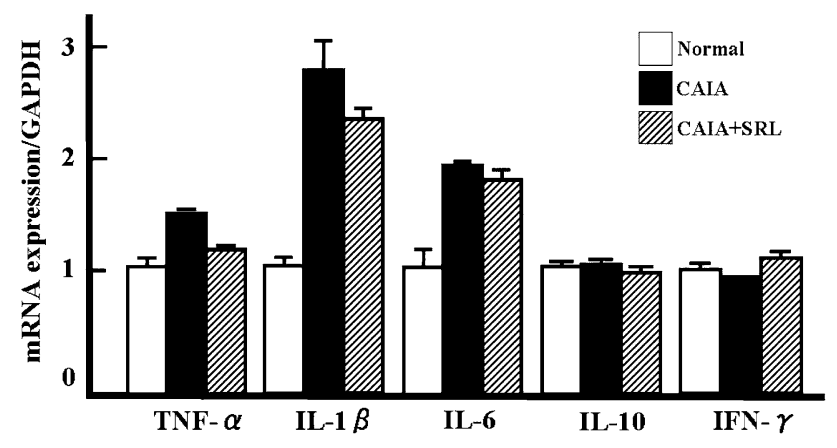

Fig. 5 mRNA levels for inflammatory mediator genes in the knee joint tissue from normal control, CAIA and CAIA + SRL mice. Knee joints were harvested on day 7 after LPS injection. Soft tissues such as skin and muscle were removed from around each joint, and the total RNA was extracted. The mRNA levels for tumor necrosis factoralpha (TNF- $\alpha$ ), interleukin-1-beta (IL-1 $\beta$ ), IL-6, IL-10 and interferongamma (IFN- $\gamma$ ) were measured by reverse transcription (RT)-PCR. The values shown were normalized with glyceraldehyde-3-phosphate dehydrogenase transcript (GAPDH). Values are the means \pm SD $(n=6)$

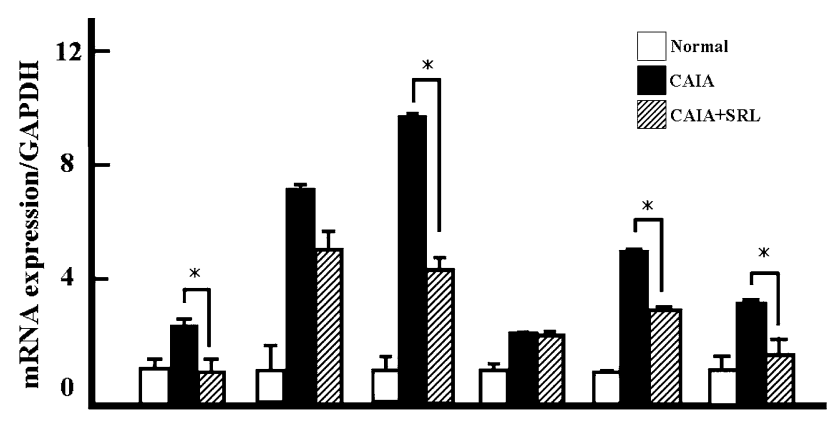

RANKL MMP-2 MMP-3 MMP-9 cathepsin c-fos

$$
\text { K }
$$

Fig. 6 mRNA levels for matrix metalloproteinase (MMP) and osteoclast-related genes in the toe joint tissue from normal control, CAIA and CAIA + SRL mice. Toe joints were harvested on day 7 after LPS injection. Soft tissues such as skin and muscle were removed from around each joint and the total RNA was extracted. The mRNA levels for receptor activator of nuclear factor-kappa B ligand (RANKL), MMP-2, MMP-3, MMP-9, cathepsin K and c-fos were measured by RT-PCR. The values shown were normalized with GAPDH. Value are the means $\pm \mathrm{SD}(n=6)$. $* P<0.05$ versus CAIA

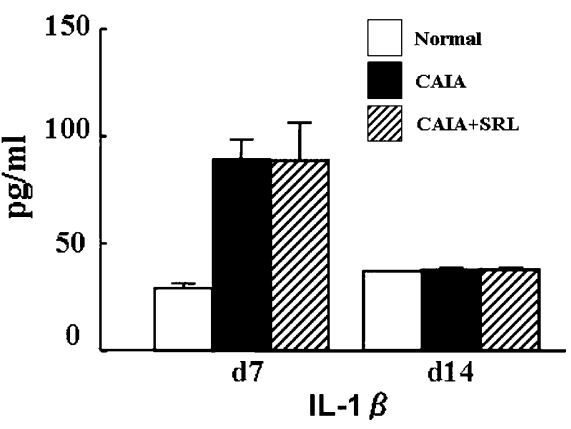

A

A Normal

CAIA

CAIA+SRL
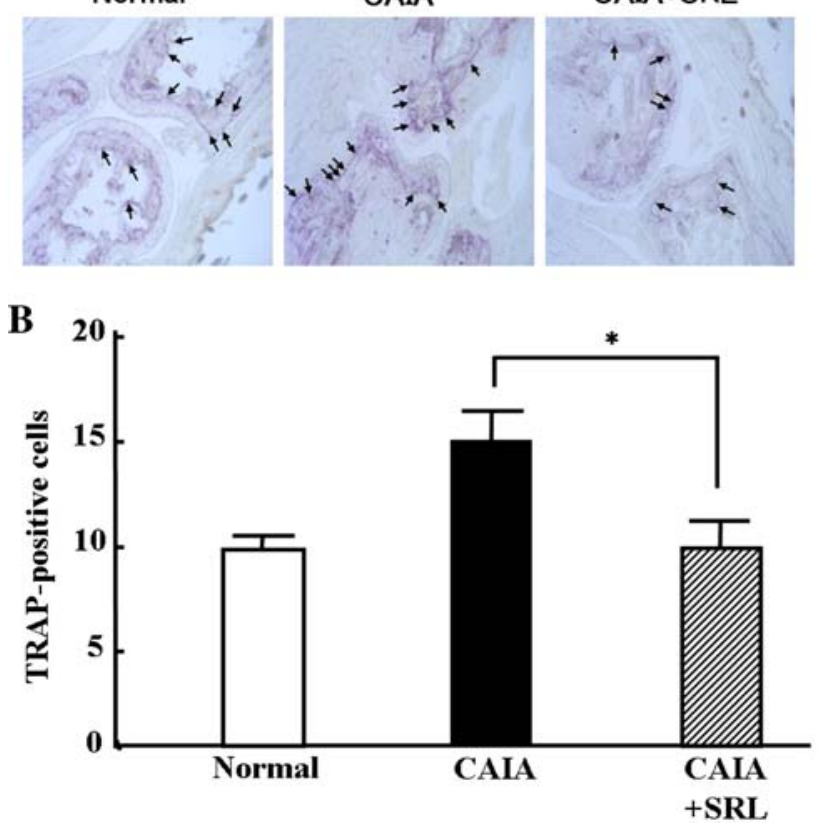

Fig. 7 Number of toe joints TRAP-positive cells in normal control, CAIA and CAIA + SRL mice. Sections were made from the toe joints of mice ( $n=6 /$ group) on day 14 after LPS injection. The sections were stained for tartrate-resistant acid phosphatase (TRAP) (a). Number of osteoclast at bone surface in each slide (number/slide) (b). Value are the means $\pm \mathrm{SD}(n=6) .{ }^{*} P<0.05$ versus CAIA. Arrows TRAP-positive cells

TRAP-positive osteoclasts were markedly reduced in the toe joints of the CAIA + SRL mice.

\section{Discussion}

RA is a systemic inflammatory autoimmune disease. The main symptoms of RA are inflammation, inflammatory cell infiltration, destruction of the joints cartilage and bone tissue. RA is usually treated with NSAIDs or corticosteroids. However, these treatments often cause severe adverse effects depending on the patient's sensitivity or the drug dosage. For example, indomethacin is an NSAID that may adversely affect gastric tissue and function [11], while 
prednisolone is a corticosteroid that can adversely affect various organs [24].

Therapeutic drugs for RA include not only anti-inflammatory drugs but also anti-rheumatic and molecular-targeted drugs. However, these drugs also often have adverse effects. For example, methotrexate is an anti-rheumatic drug that has been reported to increase the risk of interstitial pneumonia [5]. Infliximab, a molecular-targeted drug, was reported to have decreased its effect due to production of neutralizing antibody [4].

Traditional herbal therapy of RA takes advantage of using plants extracts such as SR, Uncaria tomentosa (UT) and Tripterygium wilfordii (TW) as an effective treatment alternative to established pharmacology. Moreover, herbal medicines such as SR, UT and TW have been reported to cause fewer adverse effects. UT is a significant antiinflammatory activity and an antioxidant or free radical scavenger capacity [14]. TW shows a significant immunomodulatory activity through the regulation of IL-1 and IL-2 secretion [22]. The mechanism of SR in relation to RA has not been reported yet. However, it is known that mangiferin contained in SR, regulates several gene expression in mouse liver [9].

The present study contributes to clarify the mode of action of SRL in ameliorating the signs and symptoms of RA. CAIA mice is an established model for RA. In this model, DBA/1 J mice are treated with an anti-type II collagen antibody and LPS, and fed with SRL containing diet. Our study indicates that SRL ameliorates the swelling and redness due to inflammation in paws and the inflammatory cell infiltration in joints of CAIA mice. However, SRL treatment did not affect the serum concentrations of $\mathrm{PGE}_{2}$ or IL- 1 and the levels of mRNA encoding TNF- $\alpha$, IL- 1 , IL-6, IL-10 and IFN- $\gamma$ in CAIA mice.

Osteoclastogenesis associated with RA was also beneficially affected by SRL. In this study, the treatment with SRL was associated with a decrease of the levels of mRNA encoding RANKL, MMP-2, MMP-3, cathepsin $\mathrm{K}$ and c-fos. Osteoclasts activation was also suppressed by SRL. We can hypothesize that SRL directly affects osteoclasts activity, and decrease the expression of mRNA encoding specific genes involved in osteoclastogenesis. Alternatively, it can be proposed that SRL decreases mRNA level for RANKL though stromal cells in the pannus and suppresses TRAP positive osteoclast numbers in the mice.

In conclusion, we investigated whether the symptoms of RA could be positively affected by SRL. SR contains various potentially active ingredients, other than mangiferin (MGF), such as triptotriterpenic acid B and (-)-epicatechin [29]. Detailed studies of these active ingredients targeted to clarify the mechanism of SRL on RA are warranted.
We also demonstrated that the effect of SRL is not due to a generic quenching of the inflammatory response, but it suppressed the production of degradative enzymes and osteoclastogenesis. Thus, SRL appears to have potential as a functional food or herbal medicine for RA.

Acknowledgments We thank Mr. L. Stiver, Quality Translation Co, Ltd, for useful English proofreading.

Conflict of interest statement There is no author's conflict of interest which must be stated here.

\section{References}

1. Ando W, Hashimoto J, Nampei A, Tsuboi H, Tateishi K, Ono T, Nakamura N, Ochi T, Yoshikawa H (2006) Imatinib mesylate inhibits osteoclastogenesis and joint destruction in rats with collagen-induced arthritis (CIA). J Bone Miner Metab 24:274282

2. Ainola M, Mandelin J, Liljeström M, Konttinen YT, Salo J (2008) Imbalanced expression of RANKL and osteoprotegerin mRNA in pannus tissue of rheumatoid arthritis. Clin Exp Rheumatol 26:240-246

3. Bergroth V, Zvaifler NJ, Firestein GS (1989) Cytokines in chronic inflammatory arthritis. III. Rheumatoid arthritis monocytes are not unusually sensitive to gamma-interferon, but have defective gamma-interferon-mediated HLA-DQ and HLA-DR induction. Arthritis Rheum 32:1074-1079

4. Bobbio-Pallavicini F, Alpini C, Caporali R, Avalle S, Bugatti S, Montecucco C (2004) Autoantibody profile in rheumatoid arthritis during long-term infliximab treatment. Arthritis Res Ther 6:264-272

5. Chikura B, Sathi N, Lane S, Dawson JK (2008) Variation of immunological response in methotrexate-induced pneumonitis. Rheumatology 47:1647-1650

6. Funk JL, Cordaro LA, Wei H, Benjamin JB, Yocum DE (1998) Synovium as a source of increased amino-terminal parathyroid hormone-related protein expression in rheumatoid arthritis. A possible role for locally produced parathyroid hormone-related protein in the pathogenesis of rheumatoid arthritis. J Clin Invest 101:1362-1371

7. Hayer S, Redlich K, Korb A, Hermann S, Smolen J, Schett G (2007) Tenosynovitis and osteoclast formation as the initial preclinical changes in a murine model of inflammatory arthritis. Arthritis Rheum 56:79-88

8. Honda T, Segi-Nishida E, Miyachi Y, Narumiya S (2006) Prostacyclin-IP signaling and prostaglandin E2-EP2/EP4 signaling both mediate joint inflammation in mouse collagen-induced arthritis. J Exp Med 203:325-335

9. Im R, Mano H, Matsuura T, Nakatani S, Shimizu J, Wada M (2009) Mechanisms of blood glucose-lowering effect of aqueous extract from stems of Kothala himbutu (Salacia reticulata) in the mouse. J Ethnopharmacol 121:234-240

10. Labasi JM, Petrushova N, Donovan C, McCurdy S, Lira P, Payette MM, Brissette W, Wicks JR, Audoly L, Gabel CA (2002) Absence of the P2X7 receptor alters leukocyte function and attenuates an inflammatory response. J Immunol 168:6436-6445

11. Maeda-Hagiwara M, Watanabe K (1981) Aggravating effect of ergometrine on pyloric antral lesions in indomethacin-treated animals and stimulating effect of this drug on gastric secretion. Jpn J Pharmacol 31:891-896 
12. Miyazawa S, Nishida K, Komiyama T, Nakae Y, Takeda K, Yorimitsu M, Kitamura A, Kunisada T, Ohtsuka A, Inoue H (2006) Novel transdermal photodynamic therapy using ATX$\mathrm{S} 10 . \mathrm{Na}$ (II) induces apoptosis of synovial fibroblasts and ameliorates collagen antibody-induced arthritis in mice. Rheumatol Int 26:717-725

13. Morishita K, Shirai A, Kubota M, Katakura Y, Nabeshima Y, Takeshige K, Kamiya T (2001) The progression of aging in klotho mutant mice can be modified by dietary phosphorus and zinc. J Nutr 131:3182-3188

14. Mur E, Hartig F, Eibl G, Schirmer M (2002) Randomized double blind trial of an extract from the pentacyclic alkaloid-chemotype of uncaria tomentosa for the treatment of rheumatoid arthritis. J Rheumatol 29:678-681

15. Nishida K, Komiyama T, Miyazawa S, Shen ZN, Furumatsu T, Doi H, Yoshida A, Yamana J, Yamamura M, Ninomiya Y, Inoue $\mathrm{H}$, Asahara H (2004) Histone deacetylase inhibitor suppression of autoantibody-mediated arthritis in mice via regulation of p16INK4a and p21(WAF1/Cip1) expression. Arthritis Rheum 50:3365-3376

16. Parekh RB, Dwek RA, Sutton BJ, Fernandes DL, Leung A, Stanworth D, Rademacher TW, Mizuochi T, Taniguchi T, Matsuta K et al (1985) Association of rheumatoid arthritis and primary osteoarthritis with changes in the glycosylation pattern of total serum IgG. Nature 316:452-457

17. Quattrocchi E, Dallman MJ, Feldmann M (2000) Adenovirusmediated gene transfer of CTLA-4Ig fusion protein in the suppression of experimental autoimmune arthritis. Arthritis Rheum 43:1688-1697

18. Romas E, Bakharevski O, Hards DK, Kartsogiannis V, Quinn JM, Ryan PF, Martin TJ, Gillespie MT (2000) Expression of osteoclast differentiation factor at sites of bone erosion in collageninduced arthritis. Arthritis Rheum 43:821-826

19. Shigeyama Y, Pap T, Kunzler P, Simmen BR, Gay RE, Gay S (2000) Expression of osteoclast differentiation factor in rheumatoid arthritis. Arthritis Rheum 43:2523-2530

20. Steinitz M, Izak G, Cohen S, Ehrenfeld M, Flechner I (1980) Continuous production of monoclonal rheumatoid factor by EBV-transformed lymphocytes. Nature 287:443-445

21. Takatsuna H, Asagiri M, Kubota T, Oka K, Osada T, Sugiyama C, Saito H, Aoki K, Ohya K, Takayanagi H, Umezawa K (2005)
Inhibition of RANKL-induced osteoclastogenesis by (-)DHMEQ, a novel NF-kappaB inhibitor, through downregulation of NFATc1. J Bone Miner Res 20:653-662

22. Tao X, Cai JJ, Lipsky PE (1995) The identity of immunosuppressive components of the ethyl acetate extract and chloroform methanol extract (T2) of Tripterygium wilfordii Hook. F J Pharmacol Exp Ther 272:1305-1312

23. Takayanagi $H$, Juji $T$, Miyazaki $T$, Iizuka $H$, Takahashi $T$, Isshiki M, Okada M, Tanaka Y, Koshihara Y, Oda H, Kurokawa T, Nakamura K, Tanaka S (1999) Suppression of arthritic bone destruction by adenovirus-mediated csk gene transfer to synoviocytes and osteoclasts. J Clin Invest 104:137-146

24. Thamer M, Hernán MA, Zhang Y, Cotter D, Petri M (2009) Prednisone, lupus activity, and permanent organ damage. J Rheumatol 36:560-564

25. Vaes BL, Lute C, Blom HJ, Bravenboer N, de Vries TJ, Everts V, Dhonukshe-Rutten RA, Müller M, de Groot LC, Steegenga WT (2009) Vitamin B(12) deficiency stimulates osteoclastogenesis via increased homocysteine and methylmalonic acid. Calcif Tissue Int 84:413-422

26. van Tuyl LH, Lems W, Voskuyl AE, Kerstens PJ, Garnero P, Dijkmans BA, Boers M (2008) Tight control and intensified COBRA combination treatment in early rheumatoid arthritis: 90\% remission in a pilot trial. Ann Rheum Dis 67:1574-1577

27. Woolley DE, Tetlow LC (2000) Mast cell activation and its relation to proinflammatory cytokine production in the rheumatoid lesion. Arthritis Res 2:65-74

28. Yoshikawa M, Murakami T, Yashiro K, Matsuda H (1998) Kotalanol, a potent alpha-glucosidase inhibitor with thiosugar sulfonium sulfate structure, from antidiabetic ayurvedic medicine Salacia reticulata. Chem Pharm Bull Tokyo 46:1339-1340

29. Yoshikawa M, Shimoda H, Nishida N, Takada M, Matsuda H (2002) Salacia reticulata and its polyphenolic constituents with lipase inhibitory and lipolytic activities have mild antiobesity effects in rats. J Nutr 132:1819-1824

30. Yoshikawa M, Morikawa T, Matsuda H, Tanabe G, Muraoka O (2002) Absolute stereostructure of potent alpha-glucosidase inhibitor, Salacinol, with unique thiosugar sulfonium sulfate inner salt structure from Salacia reticulata. Bioorg Med Chem $10: 1547-1554$ 